\title{
COMPETENCE-BASED EDUCATION IN COMPUTER SCIENCE AND INFORMATION TECHNOLOGIES
}

\author{
Mamarajabov M.E. ${ }^{I}$ \\ ${ }^{1}$ Candidate of pedagogical sciences, docent, Tashkent State Pedagogical University. \\ Ismoilova D.S. ${ }^{2}$ \\ ${ }^{2}$ Teacher, Fergana State University. \\ E-mail: hilola-1978@mail.ru
}

\begin{abstract}
This article intends to accentuate the contribution of Computer Science Education (CSE) fostering key competencies. Besides an outline of its contribution to convey general education a first approach of a competence model will be presented. It is elaborated within the project MoKoM granted by the German Research Foundation (DFG), which is proposed to cover competence aspects concerning informatics modeling and system comprehension. Another chapter will present relevant key competencies according to the OECD's Definition and Selection of Competencies Project (DeSeCo). Finally it will be shown, how the competence components covered by the competence model contribute to the development of key competencies within the scope of CSE.
\end{abstract}

Keywords: General Education, Lifelong Learning, Informatics Modeling Competencies, Secondary Education, System Comprehension, Key Competencies

\section{INTRODUCTION}

Every aspect of our lives today, every field and all types of activities are directly related to information and communication technologies. Therefore, the formation of knowledge, skills and abilities in each person to create and manage information technology is of fundamental importance. Informatization of the education system - speeding up the process of transfer of technological and social knowledge, creating opportunities to facilitate human adaptation to different social environments, while improving the quality of teaching and learning with the help of modern information technology.

That is why it is necessary to improve the content of education, state educational standards in the disciplines, curricula - the introduction of competence in computer science (ICT competence).

Competence is the ability to apply knowledge, skills and competencies to achieve the desired results.

Competence is the acquisition of appropriate competencies that cover the teacher's personal attitude towards himself and the subject.

A competent approach is an approach that focuses on learning outcomes. In this case, the result of training is not the sum of information acquired, but the ability of a person to act in different problematic situations.

Competence-based education is education aimed at developing students' competencies to apply the acquired knowledge, skills and abilities in their personal, professional and social activities.

Education based on a competency-based approach develops students' independence, active citizenship, initiative, rational use of media resources and information and communication technologies in their work, conscious career choice, healthy competition and cross-cultural skills.

In the work of pedagogical scientists, various aspects and components that allow to study competence more broadly and thoroughly from a pedagogical point of view have been identified and studied.

S.E. Shishov gives the following definitions of competence: 
general competence based on knowledge, experience, values and tendencies acquired as a result of learning;

the ability to make connections between knowledge and situations, to find a suitable solution to a problem (competence is permissible only if it is demonstrated in a situation, unrepresented competence is not competence, even if it is a hidden possibility).

\section{According to P.V. Simonov and L.M. Dolgov:}

competence - means the ability to act on the basis of acquired knowledge. Unlike "knowledge, skills, and competencies," which implies pattern-like behaviors, competence implies independent work experience based on universal knowledge.

"Competence is the availability of knowledge and skills in the form of social practice, which is reflected in the socio-cultural requirements of society and the results of the educational process," he said.

According to V.V. Bashev: competencies are individual abilities of a person, which are manifested in the ability of this ability to move to other conditions when conditions change. Areas of application determine their specificity and accuracy (mathematical, linguistic, political and other competencies).

Thus, competence can be interpreted as the result of competence, readiness, opportunity and, at the same time, a certain action.

According to N.A.Muslimov: competence is a certain level of formation of certain skills and professional experience in the interaction of the individual with the objects and subjects around him, which is necessary for successful activity in society as a whole and in the professional sphere in particular.

According to N.G. Vitkovskaya: Competence is the ability of a person to mobilize internal (knowledge, skills and abilities, spiritual qualities, psychological characteristics) and external (material, technical, social) capabilities aimed at solving problems.

From a psychological point of view, according to A.K. Markova: Competence is a characteristic of a particular person, that is, an individual characteristic of a person in terms of the degree of suitability for professional requirements.

The common denominator in all approaches to the definition of competence is that competence is formed and manifested in the process of practical activity.

\section{THE PURPOSE AND OBJECTIVES OF THE WORK}

Focusing the learning process on a competency-based approach requires reconsideration and development of methodological conditions in education, the content and application of new pedagogical technologies, as competencies do not apply to any subject or knowledge or skills. Since the main focus in traditional education is on the learner acquiring a certain set of knowledge, skills and competencies, today it is possible to meet people who have in-depth knowledge but cannot apply them in their place when needed or opportunity arises.

Based on the above, it is necessary to change both the content and the forms of the educational process. In this case, the modified forms should not only provide learners with knowledge on specific competencies, but also ensure that they act on their basis throughout the entire learning process. That is, the learner should not be prepared for future professional activity by forming the next set of skills, but should assimilate competencies here and now. Therefore, as a result of competency training, the following should be ensured:

- Presence of internal motivation to study as a source of self-motivation;

- the ability to organize themselves in the process of learning activities as a condition for the acquisition of integrated activities;

- the ability to differentiate (determine their own level), which allows each person to determine the level of mastery of this or that educational material;

- achievement of results of personal importance by the student;

- The existence of interconnected effective activities between all subjects of the educational process.

The competency approach is also very important for assessing the quality of education, because the main educational outcome achieved by the learner is competence, the main indicators of which are, on the one hand, compliance with educational standards and, on the other hand, individual and social needs.

A competent approach is widespread in modern world educational practice. "Competence" as a central concept combines all the knowledge and skills of the education system. In the concept of "competence" the essence of education is formed and the idea is integrated. Its objective results are the most important aspects of competence, consisting of independent activity experiences formed on the basis of universal knowledge, 
which are constantly evolving in nature, and include elements related to a wide range of cultures and activities.

Competence-oriented education is aimed at the comprehensive acquisition of knowledge and methods of practical activity that ensure success in the main areas of human activity, both for their own interests and for the benefit of society and the state.

Basic competencies are issues, knowledge, practical information and methods of activity that are relevant and promising in various areas of human life in society, the acquisition of which, on the one hand, ensures successful personal and social activities, on the other hand, a certain quality of society. to meet the needs of their resources.

In different classifications of competencies, which can be considered as basic, basic, universal competencies, proposed by researchers of foreign countries and our country, such stable groups of competencies are clearly defined that without their possession a person can live and function successfully in modern society without contradictions. .

These include:

- Competences in the field of social citizenship - ensures the social activity and civic responsibility of the subject, his participation in the activities and improvement of democratic institutions and in the political life of society, etc ;

- Competences in the field of social relations - good knowledge of written and oral and interlingual (ie knowledge of several languages), effective interpersonal and rational communication, tolerance for dissent, the correct acceptance and respect for other cultures and religions etc. provides;

- Competences in the field of information - provides an understanding of the importance of new information and telecommunications technologies, the ability to acquire and apply them, the ability to use different sources of information, readiness to work in a holistic information environment, critical thinking, etc ;

- Competences in the field of social and individual - provides the ability to properly establish family relationships and personal relationships, to treat their health and spiritual and moral qualities consciously and responsibly, to choose the right ways to spend free time, etc .;

- Competencies in the field of professional labor - the ability to analyze the situation in the labor market, to accurately assess their professional capabilities, to know the laws and ethics of labor relations, to have indepth knowledge and a broad outlook on their professional activities, to skillfully apply their knowledge and experience provides accessibility, professional qualities, etc .;

- Systemic competencies - provide the ability to study independently, both in professional and personal and social life, to acquire the skills of self-management and self-improvement, etc.

Today, there are different classifications of basic competencies in foreign science.

M. Stobart identified the following five groups of basic competencies:

1) Political and social competencies (taking responsibility, participating in joint decision-making, resolving conflicts through conciliation, participation in the activities of democratic institutions);

2) Competences in the life of a multicultural society (correct understanding of differences, mutual respect, coexistence with people of other cultures, languages and religions);

3) Competences in oral and written communication (fluency in several languages);

4) Competencies related to the emergence of the information society (mastery of new technologies, their application, the ability to be critical of information and advertising disseminated through the media);

5) Competence to receive education throughout his life, both professionally and privately, as the basis of continuing education.

ICT competence is the ability and capacity of students to effectively use information and communication technologies in the search, processing, evaluation, creation and transmission of information in order to take their rightful place in the information society and engage in successful work.

Formation and development of ICT competence in students - includes the formation and development of computer science competencies and user competencies, ie cooperation and communication, independent acquisition of knowledge and their application in practice using ICT.

\section{DISCUSSION}

4.

The basis for a person to enter into personal, social, economic and professional relationships in life, to take his place in society, to solve problems, and most importantly to be competitive in his field, profession (Communicative, information work, self-realization as a person development, socially active citizenship, 
general culture, mathematical literacy, awareness and use of scientific and technical innovations).

\section{Communicative competence}

perfect mastery of the native language and any foreign language and effective use of communication in order to interact in society;

to be able to express one's opinion clearly and concisely orally and in writing, to ask and answer questions logically based on the topic;

social flexibility, adherence to a culture of communication, ability to work in a team;

to be able to defend one's position in a conversation, respecting the opinion of the interlocutor, to convince him;

to be able to manage their passions in different conflict situations, to make the necessary (constructive) decisions in solving problems and disagreements;

\section{Competence in working with information}

access to available information sources (Internet, television, radio (audio-video recording), telephone, computer, e-mail, etc.);

adherence to media culture in the search, sorting, processing, transmission, storage, security and use of necessary information from the media;

be able to create a database, select the main ones and analyze them;

be able to work with documents encountered in daily activities (be able to write simple greeting cards, fill out questionnaires, record information about himself in the hotel list, etc.)

\section{Competence for self-development as an individual}

continuous self-development as a person, striving for physical, spiritual, mental and intellectual maturity;

continuous increase of lifelong learning, knowledge, experience independently;

adequate assessment of one's own behavior, ability to control oneself, honesty, integrity;

to be able to solve problems encountered in daily life using what they have learned and life experience.

\section{Socially active civil competence}

A sense of involvement and active participation in events, happenings and processes in society;

be aware of their civic duties and rights, and comply with them (ie be able to act as a buyer, voter, customer, producer);

to have a culture of treatment, economic and legal relations in labor and civil relations;

to serve the interests of society and his family in striving for the growth of his professional position, to be generous to those in need.

\section{General cultural competencies}

Loyalty to the Fatherland, kindness to people and belief in universal and national values;

to understand and be impressed by works of art and works of art;

dress modestly, adhere to cultural norms and healthy lifestyles,

to know the values of universal significance (customs, rituals, national and cultural traditions, etc.), to treat them with respect;

kindness, generosity, respect for the worldview, religious beliefs, national and ethnic characteristics, traditions and ceremonies of others;

careful preservation of the historical, spiritual and cultural heritage of the people, adherence to the rules of etiquette established in society.

6. Competence in knowledge and use of mathematical literacy, scientific and technical innovations 
- be able to make personal, family, professional and economic plans based on accurate calculations;

- accounting in personal, social and economic relations;

- read and use various formulas, models, drawings, graphs and diagrams in daily activities;

- to be aware of and be able to use scientific and technical innovations that facilitate human labor, increase labor productivity and lead to favorable conditions.

In addition, in the process of mastering each subject in education, students are formed competencies related to the subject, depending on the specificity of the subject, its content.

In order to ensure the continuity of the content of general secondary, secondary special, vocational education in the Republic of Uzbekistan, based on the continuity of education, aimed at educating a harmoniously developed person, basic competencies and specific competencies based on the content of each subject have been identified.

There are three types of special competencies in the field of computer science and information technology.

1. Competence to search for information and collect it in electronic media

2. Competence to process and store information in electronic media

3. Competence to transmit information by electronic means

The reason for choosing these concepts is based on the purpose and content of the study of computer science and information technology, what does computer science study? is to answer the question.

We have identified on the basis of the above 3 specific competencies, based on the content of the subject, in order to ensure the consistency of the content of general education, Informatics and Information Technology taught in general secondary, secondary special, vocational education $(9+3)$.

1. Competence to search for information and collect it in electronic media - to use information sources, to search and collect information of various forms (pictorial, coded), to sort. Use of information models, processing tools and information resources. Search and retrieve information from the Internet. Ability to adhere to ethical standards in working with information, use information and communication technologies, use e-mail and protect information.

2. Competence in processing and storage of information on electronic means - creation of documents (editing, formatting of text, table, graphic, audio, image and video information). File archiving (ZIP, RARarchivator programs). Ability to work with operating system, office programs, application software package and hardware programs. Be able to solve problems related to the representation of information on the computer, coding. Ability to perform operations on number systems. Be able to create algorithms and programs on various issues. Web processing of information.

3. Competence to transmit information by electronic means - Ability to transmit information through information and communication technologies, information security, transmission of information by e-mail, fax and video conferencing. Adherence to, use, and protection of information ethics in an informed society. Distinguish between freeware, commercial software, and licensed software.

\section{CONCLUSION}

This conceptual approach - computer science and information technology - serves as a basis for creating the content of general education, curriculum development and ensuring the continuity of science. As a practical result of these ideas and approaches, the state educational standard and subject program on the subject of "Informatics and Information Technology" in secondary schools have been developed and implemented.

In order to further improve the state educational standards and curricula based on this conceptual education, the state educational standards are being improved in cooperation with UNICEF in order to implement a conceptual approach to education and study of foreign documents. programs are being changed.

The fact that the total number of general education subjects and the number of basic and sciencerelated competencies in the course is 57-60, depending on the nature of each subject, does not take into account the difficulties faced by students in learning and mastering their competencies. Therefore, in cooperation with UNICEF, it was agreed to divide the number of disciplines into 5 disciplines. The number of basic concepts in these disciplines was reduced to 4 , and the number of disciplines in science was reduced to 2 or 3 .

The development of science and technology will not bring happiness to humanity without radical changes in the socio-spiritual, cultural and moral spheres. Its influence as a powerful force for the future of 
humanity depends in many ways on the level of morality, cultural and spiritual maturity of the people, the degree of respect for universal values and the professional and personal competence of the leader.

\section{REFERENCES}

[1] "Pan-European ICT Competence 2.0" developed for European countries. 2015

[2] Michael Henderson, Geoff Romeo. Teaching and Digital Technologies Cambridge University Press 2015

[3] S.Y.Temurov: Theoretical bases of formation of professional competence in future mathematics teachers. Tashkent: Science and Technology-2014 p.44

[4] N.Muslimov, M.Usmonoboeva, D.Sayfurov, A.Turaev: Fundamentals of pedagogical competence and creativity. Tashkent-2015, p.25

[5] N.A.Muslimov, K.M.Abdullayeva, O.A.Kuysinov, N.S.Gaipova, N.N.Karimova, M. Kadyrov: Technology of formation of professional competence of teachers of vocational education. Tashkent: Science and Technology-2013, p.32

[6] Jiyenbekovna, T. A. (2019). Formation of the system of increasing the qualification of teachers in Asian countries. European Journal of Research and Reflection in Educational Sciences: Special Issue 7(10) pp 5861.

[7] Alfiya Zhienbekovna Turekeeva ., EDUCATIONAL ISSUES IN FOREIGN EXPERIENCE.,

ACADEMICIA: An International Multidisciplinary Research Journal ., Vol. 10, Issue 6, June 2020, http://dx.doi.org/10.5958/2249-7137.2020.00528.5

[8] Irgashevich, D. A. (2020). Development of national network (tas-ix). ACADEMICIA: An International Multidisciplinary Research Journal, 10(5), 144-151. Article http://dx.doi.org/10.5958/2249$\underline{7137.2020 .00254 .2}$ 